\title{
Leonardo Favio: faces e interfaces de um certo cinema latino
}

TUNiCO AMANCIO

Universidade Federal Fluminense/UFF 


\section{Resumo}

Este artigo aborda algumas facetas dos filmes de Leonardo Favio e a relação que elas mantêm com a evolução dos contextos sociais e históricos na Argentina durante a segunda metade do século passado.

Palavras-chave

Cine Latino-Americano, Leonardo Favio, Contextos Históricose Sociais

\section{Abstract}

This article considers some facets of the Leonardo Favio's films and the relation they maintain with the evolution of social and historical contexts in Argentine during $20^{\text {th }}$ century second half

Key words

Latin American Cinema, Leonardo Favio, Historical and Social Contexts 


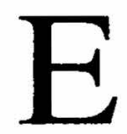

studar um cineasta argentino de pouca projeção entre nós é fato inusitado. Não sendo um nome dos mais representativos do que se convencionou chamar de nuevo cine latino-americano pior ainda. Passamos por Solanas, Getino, vagamente por Raymundo Gleiser, conhecemos um pouco de Fernando Birri, Torre Nilsson, Lautaro Murua, quiçá Armando Bo, o Carlos Hugo Christensen que acabou vindo para o Brasil. Um intervalo e depois Luiz Puenzo e Maria Luiza Bemberg, talvez por causa das indicações ao Oscar. Nosso conhecimento, imagino, estou falando antes de qualquer coisa por mim mesmo, não ultrapassa essas fronteiras até que reavivemos a figura de Juan José Campanella e tombemos sobre Lucrecia Martel, Pablo Trapero, Carlos Sorín, Fabián Bielinsky, a galeria não passa muito disto, apesar da proximidade de fronteira com a terra de Perón e Gardel, este último, como todos sabem, uruguaio ou francês, segundo a fonte.

Por isto, e a partir de uma vaga informação de que o Glauber gostava muito desse cara, que fazia um cinema muito peculiar, informação acompanhada de duas cópias chumbadas em VHS, foi a partir daí que eu acabei conhecendo Leonardo Favio, o loquito intuitivo (Oubiña e Aguilar, 1993: 7), sobre quem existem lá na Argentina também poucos livros, 4 ou 5 , mas que goza de um prestígio compatível com a singularidade de sua obra. O mais recente, de junho de 2007, é um rico e portanto caro catálogo produzido pelo Malba (Museo de Arte Latinoamericano de Buenos Aires), com o título sugestivo de "sinfonía de un sentimiento". Como se pode notar, expressões bombásticas para um realizador de algumas poucas obras que vale a pena conhecer, o que me faz trazê-lo aqui para apresentá-lo em linhas muito panorâmicas, e buscar, através dele, o que chamei de "faces e 
interfaces de um certo cinema latino", mesmo correndo o risco calculado da simplificação. No CINESUL 2007 houve uma retrospectiva de sua obra, mas a qualidade das cópias em vídeo era tão precária que vamos considerar quase um desserviço à divulgação de sua obra.

À medida que fui mergulhando nos filmes de Favio comecei a pensá-los em relação ao cinema brasileiro e no modo como esta comparação se coadunava com o que Paulo Paranaguá preconiza como sendo uma iluminação necessária de certas tendências gerais e de aspectos particulares ainda subestimados do cinema latino-americano (Paranaguá, 2000: 9).. Não creio que eu possa dar conta, aqui, desta tarefa ambiciosa, que será apenas esboçada. Por comedimento, me contentarei com as informações mais importantes sobre Favio. A comparação fica para outra etapa.

Para entender Favio, diz-se, é necessário entender-se a geração de 60 e as medidas que sacodem o país depois do golpe militar que derruba o governo de Perón em 1955. Momento em que uma ideologia liberal vai sustentar as bandeiras de "liberdade" e da "democracia" e festejar a derrota de um "totalitarismo", o que dá origem a uma aberta repressão popular: intervenções em sindicatos, deportações e fuzilamentos, proscrição do peronismo e uma crescente política de desnacionalização e de estímulos aos investimentos estrangeiros (Getino, 2005: 42). Com isto caem também os estímulos ao cinema, o fim da legislação protecionista, os créditos a produtores e a cota de tela (Oubiña e Aguilar, 1993: 11). Mas esta indústria paralisada vai dar ensejo à ascensão de pequenos produtores independentes e novos realizadores, atores e técnicos, formados no curta metragem e nos cineclubes. A obra destes cobre as lacunas do cinema industrial e gera ali um "espírito comum", voltado para a busca da autenticidade, de uma fisionomia nacional, um enfrentamento entre um cinema de expressão e um cinema espetáculo (Oubiña e Aguilar, 1993: 11-12). Esta questão vai gravitar em torno das posições de Fernando Birri e Leopoldo Torre Nilsson e vai gerar também a marca de um "nuevo cine argentino", preocupado em se opor ao cinema convencional e artificial dos estúdios. Um cinema de autor, um ar de renovação que vai se refletir num cinema urbano intelectual, 
embora pequeno-burguês e um cinema testemunhal documental politizado (Farina, 1993: 8).

Leonardo Favio se instala nesse meio-de-campo e planta aí as bases de sua dramaturgia. Ele nasce em Mendoza em 1938 com o nome de Fuad Jorge Jury e tem uma formação intuitiva e autodidata, forjada na admiração do cinema europeu.. Começa sua carreira como ator na televisão e chega ao cinema pelas mãos de Torre Nilsson, atuando em alguns filmes de prestígio, até dirigir um curta, El amigo, para o qual conseguiu negativo pedindo as latas em nome do padrinho... sem que este soubesse, naturalmente (Farina, 1993: 11). Sob a influência de Robert Bresson, Favio vai transformar sua idéia para um curta no longa metragem Crônica de un niño solo, em 1964, inaugurando o que Oubiña e Aguilar vão denominar de cine de los humildes (Oubiña e Aguilar, 1993: 13), embora Favio insista em dizer que chegou à direção para seduzir a atriz Maria Vaner, que fazia o gênero intelectual. $O$ filme é saudado como uma surpresa inovadora (Oubiña e Aguilar, 1993: 17), quando o boom da geração de 60 já começa a sucumbir às crises econômicas e à censura. Crônica de um niño solo ganhou o prêmio da crítica do Festival Internacional de Mar del Plata e Favio mudou de status, passando de ator a diretor, numa estréia convincente sobre um menino que foge de um reformatório e volta a seu povoado miserável. Um filme de tensões latentes, profundamente político e moral, com pitadas de elementos autobiográficos ( já que Favio teve uma infância pobre, vivida no universo das radionovelas onde trabalhava sua mãe, Laura Favio). A perda da inocência em meio a uma instituição social falida, numa sociedade em que a idéia de futuro não alimenta as esperanças de nenhum personagem. Além de sua temática social, o filme se ampara numa dramaturgia da forma inusitada, contrastando a geometria das vidas encarceradas com o espaço aberto do povoado. Com determinações feitas de ordenamento, de sonoridades reguladoras, com o uso intensificado da profundidade de campo, uma perspectiva mediada por janelas e venezianas, em oposição ao uso enfático da grande angular:, quando da fuga, uma sensação de errância nos longos e repetidos travellings que vão associar sua estética ao contemporâneo Os incompreendidos, de François Truffaut. Ao con- 
trário do francês, Favio mantém sua câmera implacavelmente imparcial (Oubiña e Aguilar: 28), num provocante testemunho da sociedade de sua época. Oubiña e Aguilar percebem já nesta obra a constituição de uma poética, desenhadas já as linhas estéticas que vão singularizá-la no futuro. A imagem e a narrativa se sustentam numa concepção construtivista, o ascetismo de Bresson, tornado cruel pelo aspecto definitivo de coisa vivida, à maneira de um documental novelado, sem a retórica da justiça e na periferia do Estado.

À Crônica vai suceder a película Este es el romance del Aniceto y la Francisca, de como quedó trunco, comenzó la tristeza y unas pocas cosas más, título quilométrico, de 1965/66, ainda em preto e branco, que vai narrar as desventuras do personagem principal, um desocupado que vive do fruto das rendas de seu galo de brigas Blanquito e sua relação com Francisca, logo trocada por Lucía ( a tal Maria Vaner que ele quis impressionar no começo de carreira e com quem afinal se casou!!), até que por conta de um anel é abandonado pelas duas e se vê obrigado a vender o galo a um vizinho. Quando descobre que Blanquito vai ser comido assado, Aniceto tenta roubá-lo de volta e é morto. A câmera sobe deste pátio interno até o céu onde esbarra com satélites artificiais em órbita, contrapondo esse mundinho provinciano e o cosmo, ironizando a profunda dessincronia da comunicação entre os personagens. O Aniceto solitário, como o Polín de seu filme de estréia, tem sua solidão inscrita na própria tessitura da obra, pelo uso particular da escala dos enquadramentos, combinando planos gerais e primeiros planos de modo a excluir completamente as passagens sensíveis pelos planos médios, os responsáveis pela interação dos personagens, ou ainda pelo uso acentuado do espaço sonoro off, de onde são emitidas quase todas as falas, dificultando definir se são um discurso interno ou um solilóquio dos personagens (Trerotola, 2007: 150), a palavra alheia às relações do trio principal. São imagens e falas que recusam o plano-contraplano e instauram um estado de ânimo particular motivado pela lentidão da narrativa, um tempo vazio a superar o desenrolar dos acontecimentos e que vai ter seu contraponto numa peça de teatro encenada para os três personagens e que vai ser o farol desta desconstrução sintática que esbarra na quarta parede e marca os 
limites da representação. Esta cena dentro da cena remete ao mundo vivido de Favio e sua noção de espetáculo barroco cheio de paixões, momento teatral, a câmera plantada frente ao acontecimento, um plano-sequência que funciona como um espelho invertido do cinema e exalta os artistas ambulantes da arte popular.

Uma certa crítica vai reagir com estupefação, comparando o filme a "uma postura de yoga difícil" (Fouz, 2007: 151). Então, em 1966/68 será a vez de $E l$ dependiente (O balconista) Fernandez, que trabalha há 25 anos para Don Vila esperando vê-lo morrer para herdar a sua lojinha de ferragens...e ingressar no Rotary Club local. Uma vida feita sobre a reiteração dos mesmos hábitos e gestos de que a tripla repetição de um mesmo travelling será o corolário no momento de seu encontro com a Senhorita Plasini. A ação se alterna entre o dia na loja e a noite junto a ela e sua mãe e depois o irmão amalucado, uma estrutura temporal de um inferno circular, um eterno retorno que a voz do próprio Favio narra em off. Fernández é um analfabeto afetivo que nunca age, e que vai frequientar o templo espírita que a família Plasini mantém, com patético e reservado pudor. Don Vila morre e uma vez rompida a relação pai-filho, Férnandez parte para a consecução de seu plano, já no carro fúnebre é provocado a manter relações com a moça e, morando com ela, descobre que a vida de casado nada mais é do que a repetição da vida anterior. Dependente, descentrado, o personagem vive a obsessão da reiteração dos gestos e atos de sua vida, que vão contaminar a narrativa e se inscrever nas imagens do filme. Os travellings iniciais, as visitas sempre repetidas e trabalhadas nos sintomáticos modelos de enquadramento, os primeiros planos marcados sobre fundo neutro, a câmera colada no rosto dos atores a observar suas expressões feitas de excessos nada naturalistas, a interdição diária das 11 horas, quando ele deve partir. Em $O$ Balconista, o plano médio é recuperado para evidenciar esta disjunção dos personagens postos em contato e sem nenhuma relação possível. Um processo que pulsa na composição da trama até a saturação marcada pelo longo travelling final, que sai da mesạ de jantar do porão, atravessa a loja de ferragens e corre pelas ruas, se apartando do local onde Fernandez acaba de envenenar a comida que ele e a esposa jantam. El dependiente encerra o 
ciclo preto e branco de Favio, voltado para um mergulho no social. E ele vai tentar filmar a vida do anarquista Severino di Giovanni, de Simon Bolívar e Jesus Cristo, sem sucesso. Favio tenta o suicídio. Então decide dar uma guinada em sua carreira e se transforma em cantor e como tal se apresenta nos filmes Fuíste mia um verano ( 1969) de Eduardo Calcagno e Simplemente una rosa (1971) de Emilio Vieyra, filmes que obtiveram estrondoso sucesso popular. Ele junta dinheiro para produzir seu novo filme, agora como figura conhecida do público, o queridinho das moças dizendo "basta de filmes para cineclubes... não quero fazer filmes para as elites, sou povo e dou cultura ao povo: que ele a queira aproveitar é outra coisa." Estas falas têm a ver com o.retorno de Perón do exílio e com o clima do país: ( ao contrário do resto do continente, depois dos exílios de cineastas brasileiros e bolivianos, do fechamento político da cinemateca de Montevidéu e da prisão dos cineastas colombianos, quase no mesmo momento em que os chilenos abandonavam seu país), na festa da expectativa de libertação nacional. A eleição de Perón, acompanhado de Isabelita, vai celebrar o estrondoso êxito comercial do filme Juan Moreira ( 1972), o turning point na carreira de Favio em direção ao cinema-espetáculo e a um contato mais direto com o estado de ânimo argentino, voltado naquele instante para a afirmação de sua identidade nacional. Lembrar que só mais tarde, em 1974, corn a morte de Perón, a Argentina vai ver radicalizado o jogo político por muitas décadas. E que; naquele momento, a história do gaúcho Juan Moreira, baseada num folhetim homônimo de Eduardo Gutierrez, vai estar inserida num ciclo de argentinização do cinema, (1968 a 1972) um revisionismo histórico do nacionalismo patrocinado pelo Estado ( como vai acontecer também no Brasil) e vai ser transformada por Favio num road movie sobre um gaúcho infame. $O$ filme deveria se chamar La vida del Juan Moreira, en colores, con sonido y todo. A pedido del cariñoso público, mas finalmente ficou simplificado. Uma explosão de objetos e cores, uso intenso de amanheceres e entardeceres, música epifânica, o tempo pensado não como o tempo do mito, mas da atualidade, neste quase western passado no pampa, o herói exilado de um mundo em crise. Favio segue com os planos seqüências e recorre ainda à voz off para dar 
sentido histórico a esta fábula sobre a marginalização e os abusos do poder, como um derradeiro sinal de uma "derrota inevitável, uma homenagem antecipada aos que poucos anos depois dariam suas vidas na noite da última ditadura" (ROJAS, 2007: 156). Então Favio embarca em seu segundo sucesso popular, num filme estranhíssimo feito em 1974-1975, onde Nazareno vai se apaixonar por Grisela e pela ação do diabo vai renunciar ao poder e à riqueza pelo amor da moça. Como castigo será transformado em lobo e nas noites de lua cheia sairá em busca de rebanhos, até ser caçado pelo pai da moça e morto juntamente com ela. Favio vai radicalizar seu projeto de cinema e vai misturar suas fontes: a música de opera com música popular, vestimentas atemporais com maquiagem incongruente, figuras mitológicas com trupes circenses, montando camadas de significação que nos lembram muitos dos procedimentos do tropicalismo ou da trilogia do amor de Pasolini, filmada na mesma época. Nazareno Cruz y el Lobo vai lidar com uma leitura visual das lendas populares, dando-lhes uma embalagem melodramática e modernosa, com um tratamento ilusionista que lembra o realismo mágico, uma encenação barroca capaz de superar as limitações da radionovela em que foi baseada. Favio inverte os pólos e estimula nossa identificação com o jovem monstro, despindo a cena amorosa do sopro romântico e fazendo-a quase caricata, próxima dos comerciais de televisão, gritada e cheia de câmeras lentas, pudicos nus sob cachoeiras, e uma inverossímil corrida de biga à la Cecil B. de Mille, levada pelos dois enamorados. A desmesura de Fávio constrói um halo mágico em todo o filme e transgride radicalmente o mundo dos mitos, levando seus herois à perdição do amor, punidos pela sua fuga da solidão.

Depois desses dois êxitos, Leonardo Favio vai sucumbir a um fragoroso fracasso comercial e de crítica. Soñar, soñar, não por acaso meu filme favorito, foi feito em 1975/1976 e hoje é a mais revalorizada de suas obras, totalmente cult. O filme é uma quase comédia que reúne um par de não atores: o campeão mundial de boxe Carlos Monzón e o cantor Gianfranco Pagliaro, respectivamente Charly e Mario. Filmada nos últimos meses do governo de Isabel Perón e estreada pouco depois do golpe de março de 1976, a fita lida com o fracasso desses artistas ambulantes e seus pequenos golpes, 
que garantem sua sobrevivência. O final é emblemático, depois de muitas aventuras, os dois acabam fazendo seu espetáculo atrás das grades. "Já estávamos todos presos", diria Favio (Noriega, 2007: 157). O grotesco contamina toda a narrativa e subverte qualquer expectativa quanto a um cinema regrado, e porque ele continua buscando a invenção formal, o filme parece mal costurado e quase amador, não pulsasse nele a vibração do espetáculo popular, na sua versão de cidade do interior. Mario acha que Carlos se parece com Charles Bronson e o convence a vender a casa e ir com ele para Buenos Aires. Carlos vai tentar a vida de artista e não vai dar certo, passando até mesmo pelo cinema argentino, onde não conseguirá dizer suas falas e sequer montar no cavalo. Mario vai fazer um roubo e os dois vão para a cadeia. Dito assim, o enredo parece banal. $\mathrm{E}$ o é, não fora a irresistível sucessão de cenas de puro cinema: Mario cantando no bar, dublando Charles Aznavour, as duas vozes se superpondo, a câmera colada no seu rosto; os dois se enfeitando com rolinhos nos cabelos, uma inesperada relação homossexual insinuada, a descoberta de que a Carmen que Mario entrevê na cidade grande não é uma sedutora mulher, mas um enérgico anão, que vai trazer ciúmes e discórdia ao trio, tudo conspira contra a expectativa popular quanto ao filme, quanto à imagem pública de seus atores ( 0 pugilista e o cantor sedutor) e marca mais a imagem de Favio, àquela altura já proscrito nas listas negras do regime ditatorial. Mais uma vez, perdedores, na tela e fora dela.

Favio se retira e só volta em 1993, com Gatica, el mono, desta vez um boxeador como tema, baseada numa história real, um grande espetáculo da recriação da história, mítico, saindo do mundo rural e suburbano e assumindo enfim a cidade como campo da modernidade e da contradição. Gatica é a história da amizade entre dois homens e a derrocada de um deles, cheio de um inesgotável orgulho de perdedor. Um filme peronista, cheio da emoção do peronismo, um passar a limpo da Argentina do século XX, Evita tratada como uma santa, Gatica como um fiel que derrama seu sangue no altar da história, multidões, tango e a celebração de um mundo submerso pela globalização e pela fatalidade. "Gatica sabe, e os espectadores com ele, que é portador do envergonhante, embora resis- 
tente, vírus dos excluídos. Nenhum gesto poderá restituir-lhe o que desde a origem lhe foi tirado" (Getino, 2005: 127). Favio é o engenhoso artífice dessa anunciação.

Entre 1994 e 1999 Favio se envolveu na realização de seu projeto mais ambicioso: Perón: Sinfonia del sentimiento, uma obra inclassificável, uma encomenda de Eduardo Duhalde, com fins eleitorais, que tropeça nos planos de Carlos Menem e que deixa de ser um material promocional para se transformar em um épico de seis horas de duração, misturando técnicas, pensando apaixonadamente, em um anacronismo que reivindica a intervenção do estado na vida argentina, o cine panfleto virando cine poesia e ambas se misturando. A aventura cinematográfica de Favio prossegue, ainda surpreendendo aos 70 anos: em 2008 ele estréia Aniceto, uma refilmagem de sua obra de 1965, agora em forma de musical, números de dança entre lençóis estendidos num varal e uma inversão do triângulo do filme original. É Favio de novo entre música e imagem refazendo sua particular leitura da sociedade argentina.

Apesar de este ser um olhar muito apressado sobre a obra de Leonardo Favio, ele continua a me parecer uma excelente tela onde talvez possamos espelhar algumas das características comuns de um cinema latino-americano. Me intrigam particularmente seus filmes feitos entre 72 e 76, o que associaríamos no Brasil à fase EMBRAFILME e sua busca de contato com as platéias populares. Suas estratégias retóricas merecem ser melhor pensadas para que talvez, colocadas em perspectiva com um certo cinema brasileiro, possam iluminar melhor a fatura de filmes singulares que buscaram, naquela época, um outro diálogo com o seu público. 


\section{BIBLIOGRAFIA}

FARINA, Alberto. Los directores del cine argentino. Buenos Aires: -Centro editor de América Latina, 1993.

FOUZ, Javier Porta. In Adrián Cangi (org.) Favio: Sinfonía de un sentimiento. Buenos Aires: Fundación Eduardo F. Constantini, 2007.

GETINO, Octavio. Cine argentino: entre lo posible y lo deseable. - Buenos Aires: Ciccus, 2005.

NORIEGA, Gustavo. In Adrián Cangi (org.) Favio: Sinfonía de un sentimiento. Buenos Aires: Fundación Eduardo F. Constantini, 2007.

OUBIÑA, David e AGUILAR, Gonzalo Moisés. De como Leonar:do Favio contó el dolor y el amor de su gente, emocionó el cariñoso público, trazó nuevos rumbos para entender la imagen y otras reflexiones. Buenos Aires: Nuevo Extremo, 1993.

PARANAGUÁ, Paulo Antônio:i Paris: L’Harmattan, 2000.

TREROTOLA, Diego. In Adrián Cangi (org:) Favio: Sinfonía de un sentimiento. Buenos Aires: Fundación Eduardo F. Constantini, 2007. 